\title{
Towards Understanding a Distinct Hydrogen Peroxide Electrocatalytic Enhancement Using Surfactant-Based
Coatings on Silver
} $\operatorname{sins}$

\author{
A. Goodison ${ }^{\text {, L. Gonzalez-Macia }}{ }^{\mathrm{b}}$, A. J. Killard ${ }^{\mathrm{b}}$, A. Morrin ${ }^{\mathrm{a}}$ \\ a School of Chemical Sciences, National Centre for Sensor Research, \\ Dublin City University, Dublin 9, Ireland
}

${ }^{b}$ Centre for Research in Biosciences, Department of Applied Sciences, University of the West of England, Coldharbour Lane, Bristol BS16 $1 Q Y, U K$

\begin{abstract}
The detection of hydrogen peroxide has been shown to be very important in recent years due to its relevant role in many industrial applications as well as biological reactions. We are interested in it as a quantitative marker for oxidase-based biosensor applications where it is produced when substrate (e.g., glucose, cholesterol) is catalysed by its respective oxidase enzyme.

Previously, a commercial silver flake-based screen-printing ink (PF-410, Acheson ${ }^{\circledR}$ ), when coated with surfactant and salt (dodecylbenzenesulfonic acid (DBSA) and $\mathrm{KCl}$ ) has shown to significantly enhance the electrochemical reduction of hydrogen peroxide - up to 80-fold over non-treated inks. In this study, the silver morphology, presence of dispersant and silver supplier is investigated for their effects on the electrocatalysis of hydrogen peroxide. In order to do this, inks loaded with silver micron-sized flakes and silver nanopowders, from various suppliers, are prepared using the binder material extracted from the Acheson ${ }^{\circledR} \mathrm{PF}-410$ to formulate inks.
\end{abstract}

\section{$\mathrm{H}_{2} \mathrm{O}_{2}$ electrocatalytic study}

The study of the effect of silver source, morphology and particle size was done by blending various $\mathrm{Ag}$ materials with a binder/carrier system from the Acheson ${ }^{\circledR}$ PF-410 ink. This binder/carrier solution was obtained by a simple centrifugation to remove silver. This binder solution was then blended with the different types of silver $(75 \% \mathrm{w} / \mathrm{w})$ and their electrocatalysis of $\mathrm{H}_{2} \mathrm{O}_{2}$ was studied by dip-coating the various silver conductive inks on glassy carbon (GC) electrodes. Films were cured at $120^{\circ} \mathrm{C}$ for $5 \mathrm{~min}$. Analysis was done using amperometry (-0.1 V vs $\mathrm{Ag} / \mathrm{AgCl}$ in $\mathrm{PBS} \mathrm{pH}$ 7.4). A surfactant/salt solution was used to modify the electrodes by dipping the modified GC electrodes into $3.3 \times 10^{-2} \mathrm{M} \mathrm{DBSA} / 0.1 \mathrm{M} \mathrm{KCl}$ for at least $30 \mathrm{~min}$ before electrocatalysis.

Electrocatalysis on $\mathrm{Ag}$ and surfactant/salt modified Ag films
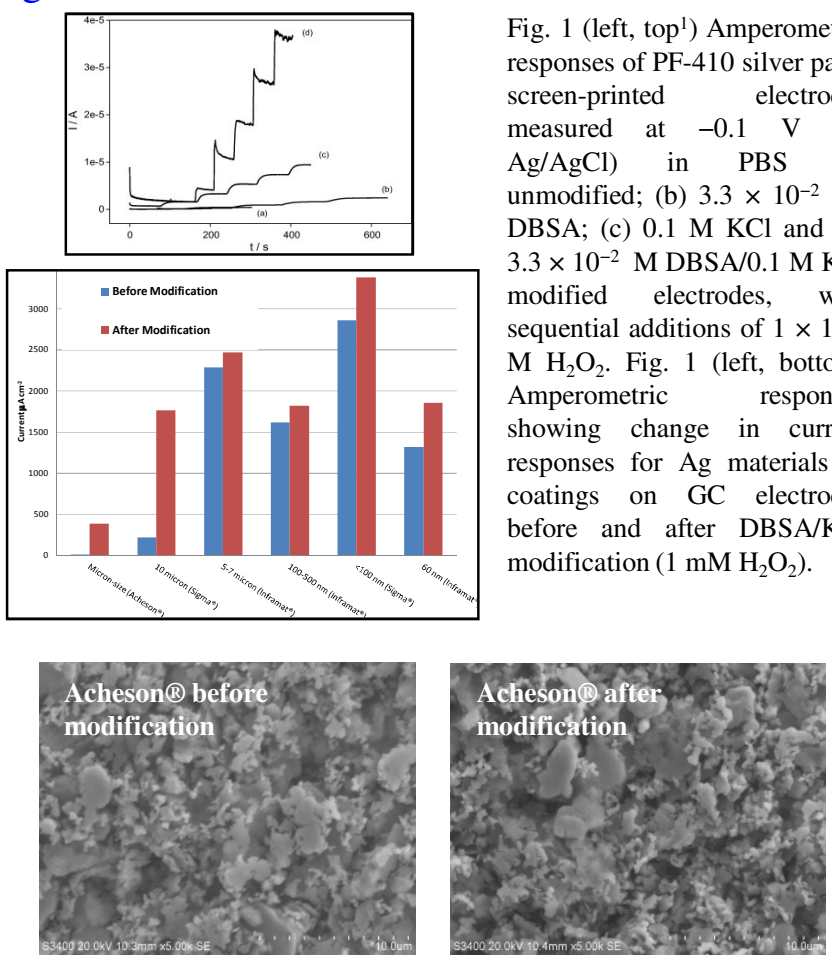

Film comprising Acheson ${ }^{\circledR} \mathrm{Ag}$ (left) shows the surface of the cured coating to contain micron-sized silver flakes of varying sizes. The DBSA/KCl modified Acheson ${ }^{\circledR}$ surface (right) shows no obvious change in morphology despite exhibiting a 35-80-fold increase in catalytic current upon $\mathrm{H}_{2} \mathrm{O}_{2}$ catalysis. This may indicate that the modification process may not be a result of a change in physical morphology, after modification with $\mathrm{DBSA} / \mathrm{KCl}$.
Film morphologies comprising Ag particles
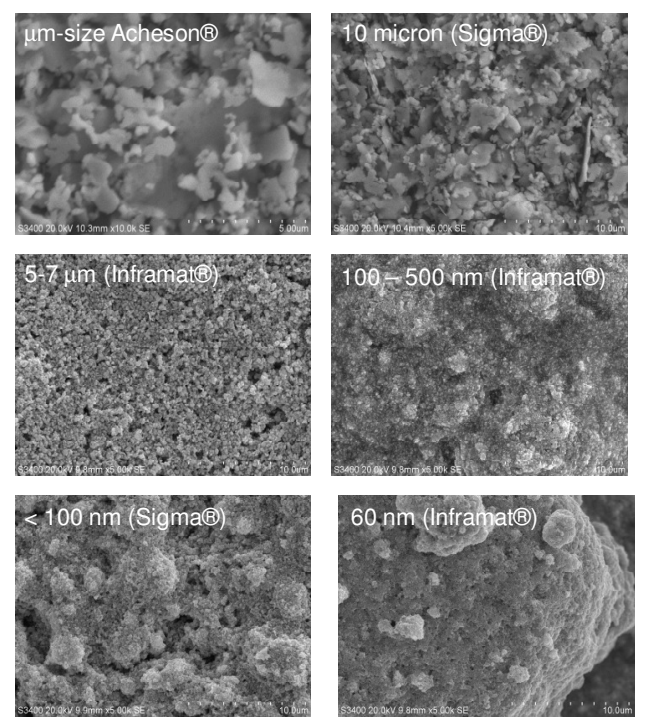

SEM images of $\mathrm{Ag}$ films showing morphologies relating to their respective particulate sizes and shapes (flakes and spherical particles). No significant differences in contact angles were observed across the different inks $\left(108.5^{\circ}+12.8 \%\right)$.

Correlation of Ag dispersant with catalytic behaviour

\begin{tabular}{|c|c|c|c|c|c|c|}
\hline Ag Material & $\begin{array}{l}\mu \mathrm{m}-\text { size }^{\prime} \\
\left(\text { Ach'n }^{\circledR}\right)\end{array}$ & $\begin{array}{l}10 \mu \mathrm{m} \\
\left(\mathrm{Sig}^{\circledR}\right)\end{array}$ & $\begin{array}{c}5-7 \mu \mathrm{m} \\
\left(\text { Inf’at }^{\circledR}\right)\end{array}$ & $\begin{array}{c}100-500 \\
n m \\
\left(\text { Inf'at }^{\circledR}\right)\end{array}$ & $\begin{array}{c}<100 \\
\mathrm{~nm} \\
\left(\mathrm{Sig}^{(}\right)\end{array}$ & $\begin{array}{c}60 \mathrm{~nm} \\
\left(\text { Inf'at }^{\circledR}\right)\end{array}$ \\
\hline $\begin{array}{l}\text { Film contact } \\
\text { angle (non- } \\
\text { modified) }\end{array}$ & 110.9 & 124.4 & 110.8 & 97.4 & 118.8 & 88.5 \\
\hline \multicolumn{7}{|c|}{ No significant trend/difference } \\
\hline Dispersant & Unknown & Pristine & PVP-like & PVP-like & PVP & PVP-like \\
\hline \multicolumn{7}{|c|}{$\begin{array}{c}\text { Presence of dispersant broadly correlates with increased catalysis on } \\
\text { non-modified Ag surface and a reduced enhancement effect upon } \\
\text { modification (Fig. 1b) }\end{array}$} \\
\hline $\begin{array}{l}\text { Dispersability } \\
\text { in water }\end{array}$ & $<5 \min$ & $0 \mathrm{~min}$ & $\begin{array}{l}<30 \\
\min \end{array}$ & $\approx 24 \mathrm{hr}$ & $\begin{array}{c}\approx 24 \\
\mathrm{hr}\end{array}$ & $<40 \mathrm{~min}$ \\
\hline \multicolumn{7}{|c|}{ Greater dispersability correlates with presence of dispersant } \\
\hline
\end{tabular}

\section{Conclusion}

Different Ag materials with regard to source, size and the presence of a dispersant have different electrocatalytic effects towards hydrogen peroxide, despite being formulated as inks in equivalent manners. The modification of the cured films comprising these materials with $\mathrm{DBSA} / \mathrm{KCl}$ has also been shown to result in different catalytic effects towards hydrogen peroxide, depending on the starting silver material. It is possible that there may be an effect due to size and/or the presence of a dispersant on the starting $\mathrm{Ag}$ material. The study is ongoing.
${ }^{1}$ Gonzalez-Macia, L., Smyth, M.R., Morrin, A., Killard, A.J. (2011). Electrochimica Acta Vol. 56, Issue 114146 - 4153

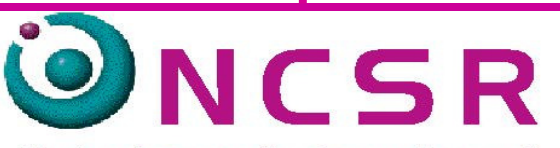

National Centre for Sensor Research

\section{Funding}

European Community's $7^{\text {th }}$ Framework Programme [FP7/2007-2013] under Grant Agreement no 257372.

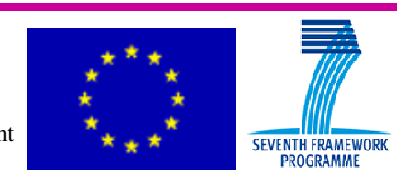

